\title{
Digital Politics: Mobilization, Engagement and Participation
}

\section{Karolina Koc-Michalska and Darren Lilleker}

A wealth of studies have explored online political communication since the early 1990s, parallel significant interest has been given to how digital technologies offer pathways to participation. We have learned from a range of studies, most of which are referenced across the essays, that digital technologies, and particular the spaces that permit social interaction, may facilitate forms of political engagement. Indications are engagement can further lead to citizen mobilisation and participation in some forms of civic life from the very local level to the supranational. While political participation on social media has been dismissed as clicktivism, and judged to be lacking in meaning or significance, others propose that political participation should not be understood as a one-dimensional but as multidimensional encompassing a range of activities. These activities include those that take place in the domain referred to as the 'electronic republic' or 'digital agora' where opinions can be expressed, understandings gained, alliances built and influence exerted vertically and, potentially, horizontally so realising the democratic ideals of collective participatory and semi-deliberative decision-making. The argument does not privilege the digital environment over the street or voting booth, rather it highlights new routes to engagement and new forms of political participation are becoming evident.

Indeed, there is much evidence that the conditions for and circumstances of political participation are adapting. Research shows a politics of disconnection with and re-alignment away from electoral politics towards a more issue-based civic engagement. While online tools can enhance learning, build communities or groups of online advocates, and facilitate a range of forms of engagement and participation it is seldom the case, the notable exception 
being Barack Obama in 2008, that these tools are utilised to engage with political parties or electoral candidates. In fact there appears a reciprocal relationship as the full potential of technologies are seldom exploited by parties or individuals who seek votes or gain election to the chambers or loci of power. Rather we find that controlled or faux interactivity is the norm in electoral political communication with little opportunity for influence and visitors required to work for the political actor or organisation rather than work with them. Citizens, reduced to the position of passive recipients of electoral and governmental political communication, use online social spaces to build networks to challenge established political elites and processes. Therefore we find a porosity between the online and offline environments which may have the potential to redefine the terms of democratic engagement.

The concept which informed the development of this edited collection of essays was to offer empirical insights into the highly complex questions around political participation in the digital age which have been the subject of significant debate. The approach here can be summarised as focusing on the question: in what ways and under what conditions does political communication via digital platforms lead to increased and enhanced levels of engagement on the part of citizens?

IN responding to this question, the special issue explores the nexus between the use of the digital environment by political actors and organisations and the extent that their colonisation of the social web enhances engagement and participation. The articles offer a range of theoretically driven discussions and analyses of empirical data in order to provide fresh thinking on the key questions relating to 'digital politics' that arise from studies to 
date. Cumulatively the studies provide some empirical insights into how use of the Internet, particularly the features associated with the second digital wave of social media might enhance engagement with electoral politics or increase patterns of disconnection in this realm of politics while increasing greater engagement with non-electoral, issue politics. In other words does the ability of citizens to access both pluralist and polarized information, interact with texts, artefacts and other users make them more likely to participate in a range of actions that can be deemed political to some extent? The work of the scholars included, all of whom have a track record for pushing the boundaries in this field, extend academic understanding of existing theoretical and empirical debates on the future of representative democracy in order to develop new understandings, applications and developments of theory to aid us to explain how the all-pervasive use of digital technology impacts upon democratic processes.

The opening essay, by Bruce Bimber, offers a theoretical discussion of civic political behavior in the changing media context in which he moves beyond the questions of who participates and how to focus on hypothesizing 'why' humans engage in social collective actions. Bimber proposes three distinct but related theoretical explanations: organization-prompted behavior (traditional forms of participation which are enhanced, and often encouraged by the adaption of organized and formally structured initiatives to digital environments), socially-prompted behavior (civic behavior based on awareness that other people are performing similar activities) and self-prompted behavior (actions which are based on personal initiative as a result of exposure to information rather than direct encouragement from organizations or other users, facilitated especially by access to a plethora of social media and the resultant lowered costs of such actions). The subsequent papers included in this special issue are bound around this theoretical approach focusing on incentives or/and 
encouragement (Lilleker and Koc-Michalska, Gil de Zuniga et al, Vaccari) or how distinct forms of organizational-prompted participation (Gibson et al) and socially-prompted participation (Skoric et al) take place in a digital media environment.

Darren G. Lilleker and Karolina Koc-Michalska use self-determination theory to develop a model to explain how patterns of political participation, offline and online, are driven by intrinsic and extrinsic motivations and mediated by the mobilization tactics of political parties, campaign organizations and peers via social media. Contrary to expectations, they find extrinsic motivations to be an overwhelming driving force of civic activities within offline and online spheres. Political participation is not a private activity, they find, but a pro-social experience involving rewards through interaction. Campaign organizations' messages reaching citizens through social media have the strongest mobilizing effect, highlighting the move to a more issue-based civic culture.

Homero Gil de Zúñiga, Matthew Barnidge and Andrés Scherman propose a model of political participation based on a new concept of social media social capital. By examining the reciprocal relation between the two dimensions of social capital, they suggest that it is social media social capital that triggers the traditional (offline) social capital rather than the other way around. They examine the mediating power of both social capital dimensions on political activities, finding social media social capital as the consistently stronger explanatory factor regardless of the environment (offline or online) or circumstance (voting or notvoting) for political participation.

In the essay covering motivations and incentives Christian Vaccari focuses on the effects of external incentives (general importance within a country) and organizational online encouragement (via e-mail and social media) on political activity within three European 
countries (Germany, Italy and United Kingdom). He finds that online mobilization positively influences the propensity to be politically active regardless of other factors, with a particularly strong effect on those who pay lower levels of attention to politics. Thus Vaccari claims a potential positive influence from digital mobilization for potentially reinvigorating democratic participation especially among more politically passive citizens.

The final two essays focus exclusively on mobilization, beginning with the essay of Rachel Gibson, Fabienne Greffet and Marta Cantijoch, where the authors explore the potential digital technology offers for facilitating the engagement of different groups of the public when prompted by political organizations. They conceptualize three distinct modes of participation which can occur within a political party's digital environment based on engagement intensity. First citizens can participate as an audience, the largest but most passive group who simply receive party communication without necessarily being a part of any community. Secondly, citizens can be friends of the party by joining the community and engaging in acts which endorse the organization, liking and sharing for example. Finally there are a minority of digital activists, a highly engaged and active group who perform the role of co-producers of party communication. Interestingly, digital activists are distinct by their dissatisfaction with the functioning of democracy, thus constituting a group of critical citizens who retain a high level of self-efficacy and trust in politicians.

In the closing essay, Marko Skoric, Qinfeng Zhu and Chris Shen conceptualize selective avoidance on social media, the act of cutting oneself off from ideologically diametric peers by breaking social ties in times of political tension. The authors claim that at a time of political conflict and polarization social media may not play the role of facilitating heterogeneous dialogue but rather, through avoiding those with conflicting standpoints, 
create an out-group identity (with the effect stronger for those within groups who perceive the greater external threat). Such socially-prompted action among a like-minded community (especially in the action of unfriending those with a dissonant point of view) is found to be related to participation in offline protest action, in particular in support of noninstitutionalized campaign organizations. The results of this paper leave us with the normative question whether the acts of ghettoing and shielding oneself from those with diametrically opposing views is a barrier for constructing a deliberative democracy.

Cumulatively, therefore, we offer a theoretical framework for understanding political participation in a digital age and subsequent articles test that framework to demonstrate that organizations can act as mobilisers, but also social prompts and more personal intrinsic motivations also play a role in determining patterns of engagement and participation. We therefore find in a digital age, social media users are exposed to multiple channels of influence within a highly fluid and complex communication agora. Politics may no longer be entirely avoidable, yet certain viewpoints might be. Equally some forms of organizations may struggle to have a share of voice within this febrile and fast moving environment.

Democracy is said to rest on the power of people, coming together to solve collective problems or, more typically, selecting representatives who develop mutually acceptable solutions for their societies. The question is the extent to which this model is being challenged in the digital era: if more deliberative and engaging forms of politics are emerging in online and offline public spaces and how people are encouraged to become active. The public displays of political opinions, attitudes and preferences feed into a complex communicative ecosystem within which a range of messages circulate, some seen by millions some seen by a small few. Some messages lead to action, some do not; some people 
are empowered, some are not. The essays here demonstrate the complex nature of this environment, the unpredictability of the patterns of influence across different individuals in different contexts, and so suggest this is an area fruitful for significant future study. Our essays offer some insights into the conditions for stimulating political participation in the digital age within some contexts and offer pointers we can use to build understanding and develop this research agenda further. 